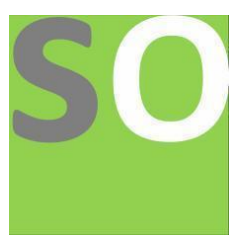

Article title: Indomethacin in COVID-19, more than just NSAID

Authors: Khaled Sorour [1], Hadeer El-Menshawy[2]

Affiliations: Bachelor of Pharmacy, the British University in Egypt (BUE)[1], Faculty of Medicine, Al-Azhar University for Girls, Cairo, Egypt[2]

Orcid ids: 0000-0001-8455-1480[1]

Contact e-mail: khaled151026@bue.edu.eg

License information: This work has been published open access under Creative Commons Attribution License http://creativecommons.org/licenses/by/4.0/, which permits unrestricted use, distribution, and reproduction in any medium, provided the original work is properly cited. Conditions, terms of use and publishing policy can be found at https://www.scienceopen.com/.

Preprint statement: This article is a preprint and has not been peer-reviewed, under consideration and submitted to ScienceOpen Preprints for open peer review.

Funder: Not applicable

DOI: 10.14293/S2199-1006.1.SOR-.PPJ4IMY.v1

Preprint first posted online: 03 April 2021

Keywords: SARS-CoV-2, COVID-19, Cytokines, Indomethacin , PPAR- gamma, HIF-1 alpha 


\section{Indomethacin in covid-19, more than just NSAID}

(An opinion article)

Authors:

Khaled Sorour $^{\mathrm{a}}$ and Hadeer El- Menshawy ${ }^{\mathrm{b}}$

${ }^{a}$ Bachelor of clinical pharmacy, British university in Egypt (BUE), El- Sherouk city, Cairo, Egypt

Phone No. +201060576515

${ }^{\mathrm{b}}$ Faculty of medicine, Al-Azhar university for girls, Cairo, Egypt

Correspondence should be addressed to (khaled151026@bue.edu.eg)

Key words:

Indomethacin, SARS-CoV-2, COVID-19, PPAR- $\gamma$, HIF-1 $\alpha$.

Disclosure: The authors declare no conflicts of interest.

Funding: NA 


\title{
Indomethacin in covid-19, more than just NSAID
}

\author{
(An opinion article)
}

As the drastic effects of SARS-CoV-2 was proven to be primarily triggered by inflammatory responses, Indomethacin could play a dual role in reversing these effects besides its reported antiviral activity. Previously, Indomethacin showed virucidal effects against VSV, SARS-CoV-1, SARS-CoV-2 in vitro and $\mathbf{C C V}$ in vivo without inducing cellular toxicity ${ }^{[1-3]}$. The reported mechanism is thought to be due to the inhibition of the viral protein translation through the activation of PKR with subsequent phosphorylation of elF-2 alpha impacting viral replication. Preliminary reports stated that the SARSCoV-2 NP-7 which is part of the viral replicase-transcriptase complex potentially binds to PTGES-2 which could be also inhibited by Indomethacin ${ }^{[4]}$.

Moreover, Indomethacin could bind and increase the expression of the immunomodulatory transcriptional factor PPAR- $\boldsymbol{\gamma}^{[5]}$. This may allow to tackle down the hyperactive immune system, and decrease the high pool of circulating cytokines during SARS-CoV-2 infection ${ }^{[6]}$. PPAR- $\gamma$ decreases the production of the pro-inflammatory cytokines IL-6, IL-1B, TNF- $\alpha$, IL-12 and controls macrophage functions while its deletion has resulted in a prominent increase in their activity combined with a decrease in the production of the anti-inflammatory cytokines such as IL-10 ${ }^{[7]}$. Extensive alveolar damage was the most remarkable manifestation observed in autopsies obtained from COVID-19 deceased patients ${ }^{[8]}$. Mall et al, demonstrated the efficacy of Indomethacin in the protection against Bleomycin-induced fibrosing alveolitis ${ }^{[9]}$. In context, PPAR- $\boldsymbol{\gamma}$ was reported to have a protective role against cytokines treated human lung epithelia through inhibition of MCP-1 ${ }^{[10]}$. The same study elucidated that PPAR- $\gamma$ is highly expressed in type-II alveolar cells as compared to type-I ${ }^{[10]}$. Interestingly, earlier studies showed that SARS-CoV-2 utilizes ACE-2 as the entry point to infect cells which is predominantly expressed on type-II pneumocytes as well ${ }^{[11]}$. We speculate that the binding of Indomethacin to PPAR- $\gamma$ expressed on type-II alveolar cells allows it to counteract the effects of the virus immunologically and anti-virally in a localized form.

Furthermore, Indomethacin could also help patients experiencing hypoxia secondary to the impaired gaseous exchange at alveolar cells recover quickly through the inhibition of HIF-1a ${ }^{[12]}$. HIF$\mathbf{1 \alpha}$ is implicated in the recruitment of macrophages and lymphocytes to hypoxic regions further

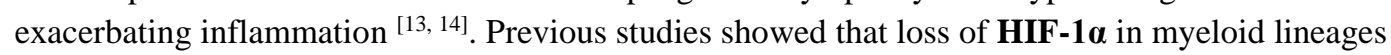
impaired their functions in terms of migration, invasion and clustering through a metabolic pathway by decreasing the availability of $\boldsymbol{A T P}$ leading to a decline in the magnitude of inflammation and joint damage in RA ${ }^{[14]}$. In addition, aerosolized Indomethacin successfully helped patients with bronchoalveolar carcinoma having refractory bronchorrhea overcome dyspnea and regain normoxemia ${ }^{[15]}$. The same drug was shown to have a protective role against thrombi formation, a commonly reported problem with SARS-CoV-2 infection. In the study conducted by Short and colleagues, Indomethacin improved survival in rat models by $43 \%$ compared to only $17 \%$ in controls following E.Coli induced sepsis ${ }^{[16]}$.

In line with clinical trials, the administration of Indomethacin $\mathbf{7 5} \mathbf{~ m g}$ for five days along with Remedisivir reduced the time to recover in severely affected COVID-19 patients ${ }^{[17]}$. The same authors pointed that Indomethacin is superior to Paracetamol in terms of symptomatic treatment that could be replaced whenever no contraindications or gestation are present ${ }^{[17]}$. In a prior study, Indomethacin showed benefits in patients with mild form of COVID-19 who are on immunosuppressive therapy following renal engrafting with minor side effects ${ }^{[18]}$. These results are consistent with the findings reported by Rothstein and colleagues in New York ${ }^{[19]}$. The current statement of WHO does not recommend against the use of NSAIDS during COVID-19, considering its promising outcomes, Indomethacin appears to be a good choice during COVID-19 setting while it also urges the need to incorporate it in controlled double-blinded clinical trials of larger sample sizes to officially validate its actions. 


\section{Abbreviations:}

SARS-CoV-2: Severe Acute Respiratory Syndrome-Corona virus-2

VSV: Vesicular Stomatitis Virus

CCV: Canine Corona Virus

PKR: Protein Kinase R

elF-2 alpha: Eukaryotic Initiation Factor-2 alpha

NP-7: Non- structural Protein-7

PTGES-2: Prostaglandin E Synthase-2

PPAR- $\gamma$ : Peroxisome Proliferator Activated Receptor-gamma

TNF-alpha: Tumor Necrosis Factor- alpha

MCP-1: Monocyte Chemoattractant Protein-1

ACE-2: Angiotensin Converting Enzyme-2

HIF-1 $\alpha$ : Hypoxia-Inducible Factor-1 alpha

RA: Rheumatoid Arthritis

NSAIDS: Non-Steroidal Anti-inflammatory Drugs 


\section{References:}

[1] Amici, C., La Frazia, S., Brunelli, C., Balsamo, M., Angelini, M., Santoro, M.G. Inhibition of viral protein translation by Indomethacin in vesicular stomatitis virus infection: role of elF2 alpha kinase PKR. Cellular immunology 2015;17: 1391-1404.

[2] Amici, C. et al. Indomethacin has a potent antiviral activity against SARS coronavirus. Antivir Ther. 2006;11: 1021-130.

[3] Xu, T., Gao, X., Wu, Z., Selinger, D.W., Zhou, Z. Indomethacin has a potent antiviral activity against SARS CoV-2 in vitro and canine coronavirus in vivo. Biorxiv 2020.

[4] Gordon, D.E., et al. A SARS-CoV-2 protein interaction map reveals targets for drug repurposing. Nature. 2020;583: 459-468.

[5] Jurgen, M.L., Lenhards, J.M., Oliver, B.B., Ringold, G.M., Kliewer, S.A. Peroxisome Proliferatoractivated Receptors $\alpha$ and $\gamma$ are activated by Indomethacin and other Non- steroidal Anti-inflammatory Drugs. Journal of Biological Chemistry. 1997;272; 3406-3410.

[6] Fara, A., Mitrev, Z., Rosalia R.A., Asas, B.M. Cytokine storm and COVID-19: a chronicle of proinflammatory cytokines. Open Biol. 2020;10.

[7] Heming, M., et al. Peroxisome Proliferator- Activated Receptor- $\gamma$ modulates the response of macrophages to lipopolysaccharide and glucocorticoids. Frontiers in immunology. 2018;9.

[8] Wichmann, D., et al. Autopsy findings and venous thromboembolism in patients with COVID-19: a prospective cohort study. Ann Intern Med. 2020.

[9] Mall, G., et al. Prevention of bleomycin induced fibrosing alveolitis with Indomethacin: serological studies on rat lungs. Virchows Arch A Pathol Anat Histopathol. 1991;419: 339-347.

[10] Inoue, K., Kawahito, Y., \& Sano, H. Peroxisome Proliferator- Activated Receptor- $\gamma$ expression in lung. Chest. 2002; 122: 386-387.

[11] Hoffmann, M., et al. SARS-CoV-2 cell entry depends on ACE-2 and TMPRSS2 and is blocked by a clinically proven protease inhibitor. Cell. 2020;181: 271-280

[12] Jones, M.K., et al. Von Hippel Lindau tumor suppressor and HIF-1 $\alpha$ : new targets of NSAIDS inhibition of hypoxia induced angiogenesis. FASEB J. 2002;16: 264-266.

[13] Jahani, M., Dokanehiefard, S. \& Mansori, K. Hypoxia: a key feature of COVID-19 launching activation of HIF-1 $\alpha$ and cytokine storm. Journal of inflammation. 2020;17.

[14] Gaber, T., Dziurla, R., Tripmacher, R., Burmester, G.R., Buttgereit. Hypoxia inucible factor [HIF] in rheumatology: low $\mathrm{O}_{2}$ ! See what HIF can do. Ann Rheum Dis. 2005;64; 71-80.

[15] Homma, S., et al. Successful treatment of refractory bronchorrhea by inhaled Indomethacin in two patients with bronchioalveolar carcinoma. Chest. 1999; 115: 1465-1468.

[16] Short, B., Gardiner, M., \& Fletcher, J. 1071 Indomethacin improves hemodynamic and clotting studies in E.Coli induced sepsis. Pediatr Res. 1981;15. 
[17] Ravichandran, R., Purna, P., Vijayaragavan, S., Kalavakollu, R.T., Gaidhane, S., Kumar, R.K. Efficacy and safety of Indomethacin in COVID-19 patients. Medrxiv. 2020.

[18] Kanakaraj, A. \& Ravichandran, R. Low dose Indomethacin in the outpatient treatment of COVID19 in kidney transplant recipients- a case series. Open Access Library Journal. 2020;7.

[19] Rothstein, R., Liebowitz, J.S., Benjamine, A., Clark, C. Rapid response to: Non-steroidal antiinflammatory drugs and Covid-19. BMJ. 2020;368. 